\title{
Acute care surgery, trauma and disaster relief: a clinical exchange between the University of British Columbia and the Mexican Red Cross
}

\author{
Joseph Margolick, MD \\ Lu Yin, MD \\ Shahrzad Joharifard, MD, MPH \\ Avi Afya, MD \\ Maria de los Angeles Mendoza \\ Velez, MD \\ Edgar Meza, MD \\ Salim Sohani, MBBS, MPH \\ Charlotte Laane \\ Elenor Ball-Banting, BA, PGCert \\ Emilie Joos, MD, MSc
}

Accepted Sept. 27, 2019

\section{Correspondence to: \\ E. Joos \\ Trauma Services \\ Vancouver General Hospital \\ 767 West 12th Ave. \\ Vancouver BC V5Z $1 \mathrm{M} 9$ \\ emilie.joos@vch.ca}

DOI: $10.1503 /$ cjs.004719
Background: Our objective was to establish a sustainable educational partnership and clinical exchange between the trauma services at Vancouver General Hospital (VGH) and the Mexican Red Cross hospital in Mexico City (Hospital Central de la Cruz Roja [HCCR] Polanco).

Methods: In 2017, a general surgery resident in postgraduate year 4 travelled from VGH to HCCR Polanco for the initial exchange, followed by a trauma fellow. The surgical case volumes in a month at VGH and a month at HCCR Polanco were compared. At the end of the exchange, a 36-item Likert style questionnaire was administered to the Mexican surgeons and residents who interacted with the Canadian resident and fellow during the exchange.

Results: The most commonly performed procedures on the VGH acute care surgery service were laparoscopic cholecystectomy (35\%) and laparoscopic appendectomy (17\%). The most commonly performed procedures on the VGH trauma service were chest tube insertions (24\%) and tracheostomies (24\%). The most commonly performed procedures at HCCR Polanco were surgery for penetrating abdominal trauma (19\%) and extremity trauma (13\%). The survey results indicated that the costs of travel and accommodation were obstacles to future exchanges. All survey respondents wanted to continue collaborating with Canadians on clinical and research endeavours, felt that hosting Canadian residents was a valuable experience and felt that visiting VGH would also be valuable.

Conclusion: Canadian surgical trainees gained valuable exposure to operative trauma during the exchange. The mix of operations performed at VGH and HCCR Polanco was vastly different; therefore, the exchange broadened the trainees' surgical experience. There was a unanimously positive response to the exchange among the Mexican survey respondents. This exchange is part of a long-term collaboration between our surgical centres.

Contexte : Notre objectif était d'établir un partenariat pédagogique et un échange clinique durables entre les services de traumatologie de l'Hôpital général de Vancouver (VGH) et de l'hôpital de la Croix-Rouge mexicaine à Mexico (Hospital Central de la Cruz Roja [HCCR] Polanco).

Méthodes : En 2017, un résident R4 en chirurgie générale du VGH s'est rendu au HCCR Polanco pour l'échange inaugural; un fellow en traumatologie l'a suivi peu après. Les volumes de cas de chirurgie par mois dans les 2 hôpitaux ont été comparés. À la fin de l'échange, les chirurgiens et les résidents mexicains qui ont interagi avec le résident et le fellow canadiens ont répondu à un questionnaire en 36 points s'apparentant à l'échelle de Likert.

Résultats : Les interventions les plus fréquemment effectuées au service chirurgical d'urgence du VGH étaient la cholécystectomie laparoscopique (35\%) et l'appendicectomie laparoscopique (17\%); au service de traumatologie, les plus fréquentes étaient l'insertion d'un drain thoracique (24\%) et la trachéotomie (24\%). Au HCCR Polanco, les interventions chirurgicales les plus courantes étaient la chirurgie pour un traumatisme abdominal pénétrant (19\%) et un traumatisme aux extrémités (13\%). Les résultats du questionnaire suggèrent que les coûts associés aux déplacements et à l'hébergement seraient un obstacle pour les échanges futurs. Cela dit, tous les répondants ont dit vouloir poursuivre leur collaboration avec les Canadiens dans des projets cliniques et de recherche, considérer que l'accueil de résidents canadiens était une expérience profitable et qu'ils gagneraient à se rendre eux-mêmes au VGH.

Conclusion : Durant l'échange, les chirurgiens en formation canadiens ont reçu une exposition précieuse à la chirurgie traumatologique. Puisque la nature et la fréquence relative des opérations effectuées au VGH étaient très différentes de celles observées au HCCR Polanco, l'échange a contribué à diversifier l'expérience chirurgicale des apprenants. Tous les répondants mexicains au questionnaire avaient une expérience positive de l'échange. Le programme fait partie d'une collaboration à long terme entre les 2 centres chirurgicaux. 
$\mathbf{P}$ articipation in international clinical electives by medical and surgical trainees has doubled over the past decade. ${ }^{1-4}$ Clinical electives abroad are opportunities to promote cross-cultural collaboration while improving trainees' communication and clinical skills. ${ }^{5}$ Furthermore, focusing international efforts on reducing the surgical disease burden in low- and middle-income countries is vital to achieving the United Nations (UN) and World Health Organization (WHO) targets of global health. ${ }^{2,6}$ There has also been growth in the development of long-term research, educational and clinical partnerships between western countries and low- and middle-income countries. ${ }^{7}$ These collaborations have afforded many opportunities for surgical residents to spend time training abroad.

Our ultimate objective is to establish sustainable clinical partnerships between the University of British Columbia Branch for International Surgical Care (UBC-BISC), located in Vancouver, Canada, and surgical centres in low- and middle-income countries. Our first step was to create a memorandum of understanding between UBC-BISC, the McGill University Health Centre - Centre for Global Surgery (MUHC-CGS) and the Canadian Red Cross. The memorandum of understanding enables the 3 organizations to work toward their mutual goal of developing bilateral educational, clinical and research exchanges with surgical departments operating under austere circumstances, such as the Mexican Red Cross. Therefore, we initiated the development of a working partnership between the surgery department at Vancouver General Hospital (VGH), which is affiliated with UBC, and the surgery department of the Mexican Red Cross Health Care Centre Polanco (Hospital Central de la Cruz Roja [HCCR] Polanco) in Mexico City, Mexico.

HCCR Polanco is the largest Mexican Red Cross hospital and the only recognized trauma centre in Mexico City. There are 4 operating rooms dedicated to emergency and trauma surgery. The hospital hosts several surgical residency programs for trauma and acute care surgery (ACS) rotations as well as medical students from 4 medical schools in the region. There is virtually no elective surgery performed at HCCR Polanco, and the majority of the trauma cases managed there involve penetrating injuries. VGH is a level 1 trauma and burn centre, an academic tertiary referral hospital and a transplant centre. The hospital houses multiple surgical services in addition to trauma and ACS, such as surgical oncology, minimally invasive surgery, advanced reconstructive surgery and cardiac surgery. VGH has 22 operating rooms and accommodates nearly 100000 emergency department visits per year. ${ }^{8}$ In contrast to HCCR Polanco, the majority of the trauma cases seen at VGH involve blunt injuries.

Surgical education is a pillar of our partnership with HCCR Polanco. Therefore, we arranged for a Canadian general surgery resident in postgraduate year 4 (PGY4) at $\mathrm{UBC}$ and a trauma fellow to travel from VGH to Mexico City for a 4-week clinical elective. We hypothesized that a clinical rotation would be a robust educational experience for the surgical trainees and would help strengthen the working relationships with our Mexican colleagues.

The objectives of the clinical elective included increasing the trainees' exposure to surgery in a foreign environment, enhancing their surgical skill and knowledge of trauma (in particular, penetrating trauma), teaching medical students and junior surgical residents and facilitating combined HCCR Polanco - VGH virtual rounds using a telecommunications application (Skype). We also sought to obtain survey data to improve future exchanges and determine the most appropriate predeparture training for Canadian trainees participating in this elective in the future. Our final objective was to endorse and help launch at HCCR Polanco a trauma registry called iTrauma, which was created by our colleagues at MUHC. ${ }^{\text {iT }}$ Trauma is a data collection platform that allows for point-of-care documentation of demographic and clinical information for trauma patients.

We hypothesized that rotating at HCCR Polanco would enable the VGH trainees to learn how to perform different trauma operations than those commonly encountered at VGH. We therefore compared the volume and variety of cases at VGH and HCCR Polanco. At the end of the rotation, we administered a Likert-style questionnaire to the attending Mexican surgeons and residents who interacted with the Canadian resident and fellow during the exchange to obtain data on Mexican participants' attitudes about bilateral global partnerships and determine how best to proceed with future exchanges.

\section{Methods}

In 2016, the Canadian Red Cross, MUHC-CGS and UBC-BISC signed a memorandum of understanding to establish the Canadian Collaborative Centre of Excellence for Global Humanitarian Surgical Care. This centre of excellence aims to pilot collaborative, bilateral, clinical and research exchanges with surgical colleagues working in austere environments. The groundwork was then set for a surgical resident from VGH to visit HCCR Polanco. In September 2017, the first PGY4 general surgery resident travelled to HCCR Polanco for a 4-week rotation, followed by a trauma fellow in April 2018. The funding for this exchange came from several sources: the Global Health Programs of the MUHC-CGS, a research grant from the UBC-BISC, and the Mexican Red Cross, which provided room and board during the rotation.

Both the visiting surgical resident and the fellow functioned as part of the surgical team at HCCR Polanco. Their clinical duties included attending to trauma activations, resuscitating patients in conjunction with other residents and nursing staff, performing bedside procedures, teaching junior colleagues, participating in daily patient rounds and attending the operating room. They were on call every third night. During their time at HCCR Polanco, 
both the surgical resident and the fellow were able to complete many trauma operations under the supervision of attending Mexican surgeons. The Canadian trainees' level of involvement in each surgery ranged from assisting other residents to being the primary operator and depended on the trainee's experience, the complexity of the operation and the presence of other trainees in the operating room. Canadian trainees were scrubbed for nearly every case and were allowed to operate at a level commensurate with Canadian residency and fellowship expectations. Cases or portions of surgical cases were allocated equitably among the trainees, and the Mexican residents shared participation in surgery amicably with the Canadian trainees.

All operations and trauma resuscitations were supervised by attending Mexican surgeons. The Canadian trainees provided input into clinical decision-making, but the final decisions were made by the attending surgeons. The Canadian resident possessed minimal Spanish language skills, and at times this affected the trainee's ability to keep up with fast-paced clinical and technical conversations. However, that trainee was still able to play an active role in clinical decision-making and patient management with the help of medical students and residents who were willing to communicate primarily in English and translate when necessary. English was the language used in the operating room by the Mexican surgeons and residents when specific instructions were provided to the Canadian trainees. Informal feedback to the Canadian trainees was provided periodically during the rotation by the Mexican surgeons. At the end of the rotation a formal UBC general surgery program evaluation was completed by the Mexican surgeons.

To compare the trainees' trauma exposure at VGH and HCCR Polanco, the surgical resident and the fellow each tracked operative cases during a 30-day period while they were rotating on the trauma service at VGH, the ACS (emergency general surgery) service at VGH and at HCCR Polanco using an online tracking tool (T-Res, available at www.t-res.net). Each case was entered into T-Res by the surgical trainees shortly after completion of the operation. T-Res enables users to record quantitative and qualitative details about the surgical procedures performed. It is the standard online tracking tool used by the UBC general surgery residency program, and it is used to track cases performed by trainees throughout the entire duration of their residency.

At the end of the rotation at HCCR Polanco, an anonymous 36-item Likert style questionnaire was administered to the attending Mexican surgeons and surgical residents using an online survey platform, SurveyMonkey. The questionnaire had an additional section in which participants could provide comments or suggestions for future exchanges. The questionnaire was written before departure by the visiting Canadian resident (J.M., the primary author of this paper) (Appendix 1, available at canjsurg.ca/004719a1). The questionnaire had 3 major themes: predeparture training for future exchanges, attitudes toward clinical and research partnerships and challenges for future exchanges. The questionnaire was administered in Spanish and the results were translated into English.

To facilitate implementation of the trauma registry, iTrauma, at HCCR Polanco, the visiting Canadian resident and fellow instructed the Mexican interns and residents at HCCR Polanco on how to complete the data form. The Canadian resident and fellow completed the iTrauma forms themselves at the point of care and helped the Mexican residents complete the forms as well. The iTrauma forms are straightforward and are available in Spanish. They are also available in an iOS-compatible iPad app; however, the institution preferred that the data be collected manually using paper forms.

In addition to experiencing day-to-day trauma cases at HCCR Polanco, the surgical resident was able to take part in a mass casualty event when a 7.1 magnitude earthquake struck Mexico City on Sept. 19, 2017. This earthquake caused widespread damage throughout the city, resulting in more than 6000 injuries and the tragic deaths of 370 people. The surgical resident helped to triage and treat more than 300 patients with earthquake-related injuries in 24 hours. During the first hour after the earthquake, many patients came to HCCR Polanco to receive care for lacerations caused by falling debris. These lacerations were rapidly sutured and the patients quickly discharged to make way for more severely injured patients. Over the next 24 hours, patients arrived in rapid succession after being extricated from collapsed buildings by the search and rescue teams. The Canadian resident took part in multiple resuscitations, assisted the orthopedic team with placing external-fixation devices for pelvic fractures and performed a lower limb fasciotomy. The resident also participated in managing patients with earthquake-related injuries once their condition was stabilized, on the ward and in the intensive care unit, which had to be expanded to accommodate the volume of patients.

After both surgical trainees returned to Vancouver, we continued the educational collaboration between VGH and HCCR Polanco by engaging in case-based, virtual teaching rounds. Participants from both institutions presented clinical trauma cases for teaching and discussion via a telecommunications application. At the time of writing, we have had 2 successful Skype rounds, as they are known, each lasting more than an hour. These rounds were facilitated by administrators with the UBC-BISC and participants included surgeons, residents and nurse clinicians from VGH and HCCR Polanco.

\section{Results}

\section{Surgical case volumes}

Over a 30-day period while rotating on the VGH ACS service, the surgical resident and fellow combined performed 
44 operations and resuscitative procedures. The most common procedures were laparoscopic cholecystectomy (35\%), laparoscopic appendectomy (17\%) and laparotomy with hernia repair (15\%, Fig. 1).

During a 30-day period rotating on the VGH trauma service, the surgical resident and fellow combined performed 52 operations and resuscitative procedures. The most com- mon procedures were chest tube insertion $(24 \%)$, tracheostomy (24\%) and gastrostomy tube insertion (20\%, Fig. 1).

Over a 30-day period at HCCR Polanco, the surgical resident and fellow combined performed 63 cases. The most common procedures were laparotomy for penetrating trauma (19\%), surgery for extremity trauma (13\%) and chest tube insertion (11\%, Fig. 1).

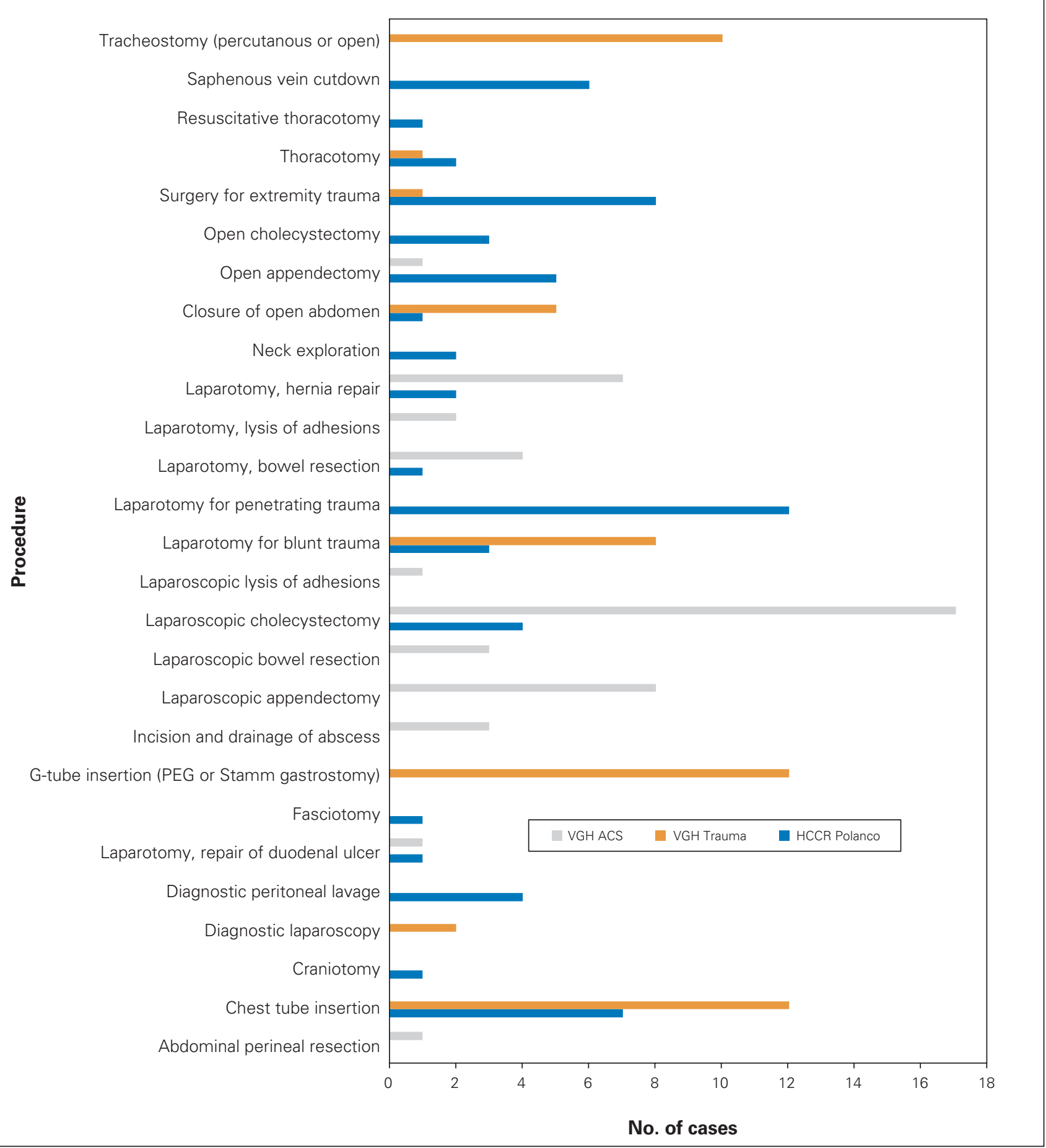

Fig. 1. Comparison of case volumes over 1 month. ACS = acute care surgery; G-tube = gastrostomy tube; HCCR = Hospital Central de la Cruz Roja; PEG = percutaneous endoscopic gastrostomy; VGH = Vancouver General Hospital. 


\section{Survey}

Survey results are reported in Table 1 . There were 7 respondents. All of the respondents felt that certification in advanced trauma life support as well as prior operative trauma experience and comfort with resuscitative procedures, such as chest tube insertion, were important skills for future Canadian participants to possess. Similarly, fellows or surgical residents in their third or higher postgraduate year were preferred as visitors to HCCR Polanco rather than junior trainees. In the comment section of the questionnaire, $43 \%$ of respondents commented that the cost of flights, meals and accommodation was an obstacle to travelling to Canada for exchanges. Similarly, $43 \%$ reported that the physical distance between the 2 institutions and the travel required to visit the institutions were barriers to an ongoing exchange. Forty-three percent of respondents thought that language and communication issues would be a challenge to future exchanges. Despite these barriers, there was a unanimous positive response to the prospect of building lasting clinical and research partnerships. One hundred percent of participants wanted to collaborate on research and conduct regular educational Skype rounds. All participants felt that there was excellent value in having Canadian trainees complete clinical electives at HCCR Polanco, and they all agreed that there would be similarly excellent value in having Mexican surgical residents complete clinical electives at VGH.

\section{Discussion}

There is significant interest in global surgery among Canadian surgical residents. ${ }^{3}$ Participating in training abroad can be an enriching clinical experience and foster professional relationships leading to lifelong collaboration. ${ }^{4}$ Of particular interest at our institution is the creation of sustainable and collaborative partnerships between western and low- and middle-income countries, rather than the pursuit of more traditional "surgical missions."

Our partnership is unique in that it involves the Red Cross movement (Canadian and Mexican Red Cross) and 2 academic institutions with firm commitments to trauma care and global surgery (MUHC-CGS and UBC-BISC). We sought to develop a sustainable, mutually beneficial exchange between VGH and HCCR Polanco. We define a sustainable clinical relationship as one that adheres to the following principles: multidisciplinary collaboration, bilateral authorship on publications, education and training, community engagement, multisource funding and outcome reporting. We felt that starting our partnership with a clinical exchange would inspire further collaboration between our 2 surgical groups. The visits of the first 2 Canadian trainees to HCCR Polanco were successful in meeting this objective. We are actively working with the surgical training program at HCCR Polanco to maintain
Table 1. Results of survey of Mexican residents and staff physicians

$\begin{array}{cc}\text { Statement } & \begin{array}{c}\% \text { of respondents who } \\ \text { agreed with statement } \\ n=7\end{array}\end{array}$

Predeparture training

ATLS experience for visiting residents is very important.

Experience with resuscitation skills is important.

Prior clinical trauma experience is important.

Visiting residents should be in their senior

years of training (PGY3 or higher).

Visiting residents should have prior

experience working in low-resource

settings.

Predeparture training should focus mainly

on procedural skills.

Predeparture training should focus on

security while visiting Mexico.

Challenges to ongoing exchange

Cost of flights, meals and accommodation

is a barrier to exchanges in Canada.

Communication and language barriers are a

challenge to ongoing exchanges.

Language barrier poses the biggest

challenge to research collaboration.

The physical distance and time required to

travel between the 2 institutions are

challenges for future exchanges.

Building a lasting partnership

Sustainable partnership

It is important to maintain clinical and

academic partnerships with hospitals

outside of Mexico.

Mexican surgical residents would benefit

from completing clinical electives in Canada

and Canadian residents benefit from

completing clinical electives in Mexico.

Research is an important component of

international exchanges.

Clinical rounds

$100 \%$ of respondents want to participate in

educational rounds via teleconference.

Research

Clinical research is an integral component of

a trauma centre.

The principal benefits of international

exchange is collaboration in research and

training.

Canadians and Mexicans should coauthor

publications.

There should be significant collaboration at

conferences and research events between

Mexican and other North American Centres.

A trauma registry would positively affect

research and patient care.

ATLS = advanced trauma life support; PGY3 = postgraduate year 3.

educational ties (through Skype rounds) and bilateral exchanges. However, because of staffing issues at HCCR Polanco and, more recently, the travel restrictions associated with the coronavirus disease 2019 (COVID-19) pandemic, this part of the collaboration is on hold. 
One of the main objectives of the collaboration is to increase surgical trainees' exposure to trauma and to enable them to develop surgical skills useful for practice in lowresource settings. Most North American residency programs do not train surgeons for this type of practice. ${ }^{10} \mathrm{~A}$ recent report comparing the case logs of humanitarian surgical missions with the case logs of an American surgical residency program found that there is a training gap in preparing surgeons to work outside of the confines of a wellresourced and well-staffed hospital. ${ }^{10}$ Clinical exchanges like ours could contribute to closing this gap. The volume of procedures performed by trainees in 30 days was comparable between VGH and HCCR Polanco. However, the case composition at the 2 institutions was vastly different. For example, the majority of abdominal surgery at VGH was laparoscopic, whereas at HCCR Polanco most abdominal surgery was performed open. Rotating at HCCR Polanco provided trainees with experience performing procedures such as open cholecystectomies and appendectomies. It is crucial for general surgeons to be comfortable with these open surgeries, especially when they are working in a low-resource setting. Similarly, exploratory laparotomy for penetrating trauma was the most common surgery performed at HCCR Polanco, whereas there were no laparotomies for penetrating trauma performed at VGH during a similar period. In addition to surgery for abdominal trauma, at HCCR Polanco the trainees were able to operate on penetrating extremity trauma, penetrating neck trauma and penetrating thoracic trauma and they learned neurosurgical and orthopedic techniques. The trainees also gained experience in performing resuscitative procedures such as saphenous vein cutdowns and diagnostic peritoneal lavage that can be useful in low-resource settings. Additionally, by training with Mexican surgeons, the Canadian trainees were exposed to several new intraoperative techniques. It is difficult to quantify exposure to these new techniques. However, any surgical trainee will attest that operating with a diverse array of surgeons who possess various intraoperative preferences can expand a learner's surgical repertoire.

The Canadian participants spent a significant amount of time teaching Mexican medical students and junior residents. Daily didactic teaching sessions were given by the Canadian trainees and Mexican chief residents. General surgery and trauma topics were discussed during these sessions. The Canadian participants also instructed junior residents on performing focused assessment with sonography for trauma (FAST) examinations and supervised laceration suturing and various other bedside procedures. Teaching provided by the Canadians was in English. The Mexican medical students and residents were proficient in English and generally appreciated the opportunity to practise their language skills.

Providing a safe educational environment for surgical trainees is critical to the success of an international elective. All parties involved in our exchange ensured that the elective in Mexico City was as safe as reasonably possible. The
Mexican hosts provided secure housing in the hospital dormitories and gave the Canadian trainees advice about how to travel safely around Mexico City. The potential dangers of spending time in Mexico City, such as robbery and violent crime, were fully discussed with participants in a transparent manner. The Canadian trainees were required to obtain international medical insurance and complete 2 formal Red Cross courses on safety and security. Overnight security at the hospital was provided by the Mexico City Police Department. Additionally, the safety and security of all hospital staff remained of paramount importance during and immediately after the earthquake. Although many nearby buildings sustained structural damage and there were thousands of casualties from the earthquake, the hospital remained structurally sound and hospital staff were not in any evident danger from falling debris. Coincidentally, the earthquake struck on the 30th anniversary of a prior destructive Mexico City earthquake. A city-wide earthquake drill to commemorate this sombre anniversary took place just hours before the new earthquake struck.

Even though there are some inherent risks associated with travelling abroad, we feel that this exchange can benefit both parties. A Mexican surgical resident visiting Canada would be able to gain more experience with the techniques and procedures commonly performed at VGH, such as laparoscopic cholecystectomies and appendectomies, central venous cannulation via the Seldinger technique, percutaneous tracheostomies and endoscopy-assisted gastrostomy tube insertion, under the supervision of Canadian surgeons. Additionally, our partnership can expose Mexican residents to a province-wide trauma system: VGH is a level 1 trauma centre as part of Trauma Services British Columbia. ${ }^{11}$ In metropolitan Mexico City, HCCR Polanco is currently the only hospital dedicated to trauma. Trauma patients in Mexico City are often brought to the nearest hospital, regardless of its resources for treating trauma victims. There are probably numerous financial, political and logistical barriers to establishing a coordinated trauma program in Mexico City. However, an organized, triage-based trauma system with dedicated trauma hospitals not only decreases mortality from trauma but is also cost effective. ${ }^{12}$ Mexican residents completing a clinical rotation at VGH may ultimately become leaders in traumatology and may perhaps incorporate elements of a Canadian trauma system into their own health care administrations.

Another principle of our sustainability definition is outcome reporting. Here, we have reported survey outcomes after a clinical exchange, which can be used to develop and strengthen this partnership. From our survey, we have learned that there is enthusiasm for continuing this clinical exchange and an appetite for collaboration between Mexican and Canadian institutions in training, education and research. We also gained valuable information that will guide the selection of future exchange participants and their predeparture training. We also identified specific 
challenges to continuing with the exchanges, such as the expenses incurred by exchange participants and communication issues. Rudimentary language skills can be learned, and we hope to blunt the cost of future exchanges by continuing to seek multisource funding.

A platform for periodic evaluation and analysis of outcomes is an essential component of an efficient trauma system. ${ }^{13,14}$ At HCCR Polanco, there is no formal trauma registry to track and analyze the demographic information, mechanisms of injury, interventions and outcomes of trauma patients. One of our secondary objectives was to endorse and assist with the implementation of a trauma database at HCCR Polanco. We introduced iTrauma at HCCR Polanco, and they are currently using it for pointof-care data collection. The data are collected electronically using iOS-compatible software on an iPad or manually using a paper checklist. Data are inputted into a computer database for future analysis. The iTrauma platform was implemented in 2015 and is used in several lowresource settings. ${ }^{15}$ Collecting medical, demographic and other data in a consistent and systematic manner may help link specific factors to outcomes, and the data that are collected can serve as a data repository for future research. At this point, research collaboration between VGH and HCCR Polanco is in the early phases, but our hope is that growth of the registry will facilitate bilateral research. Future research could employ statistical processes to study patient flow through the hospital and identify geographic hot spots of violent and nonviolent injury to inform trauma prevention policies.

Despite the overwhelming success of the first exchange with HCCR Polanco, the language barrier remained a challenge for participants. The Mexican residents, interns, students and young attending surgeons were proficient in English, but many of the older surgeons and nurses spoke little or no English. Those proficient in English often translated for the Canadians, which helped facilitate the Canadians' interaction with patients and participation in medical care. However, the Canadians found language comprehension during large group discussions to be difficult. There was always at least 1 person proficient in English during an operation who would translate instructions to the Canadian trainees as necessary. Despite the muchappreciated translation efforts of the Mexican residents and interns, the rapid tempo of discussions and the technical language used to manage sick patients were, at times, barriers to full involvement by the visiting Canadians in some aspects of patient care. We believe that although proficiency in Spanish would improve the experience of visiting Canadians, translators and online tools would enable future participants to still have a robust and educational rotation if they possessed minimal Spanish skills. Language barriers will not be a major barrier for Mexican participants coming to Canada because most of the residents are nearly fluent in English.

\section{Conclusion}

Our objective is to develop a sustainable partnership between an organization well versed in relief work (the Red Cross) and 2 academic institutions with a strong interest in global surgical care (MUHC-CGS and UBC-BISC). We believe that our initiative meets all the criteria for sustainability, through involvement of surgeons, residents, interns, medical students and administrators (multidisciplinary collaboration), collaborative publications (bilateral authorship), clinical exchange and virtual educational rounds (education and training), involvement of the Red Cross community (community engagement), diverse funding (multisource funding) and data collection (outcome reporting). Our survey indicated a unanimously positive response to the exchange by the Mexican respondents and a desire to continue working collaboratively with their Canadian counterparts. As financial support threatens the success of this exchange, we will continue to pursue multisource funding to accommodate visits to Canada by Mexican residents. Ultimately, we have succeeded in developing the foundation for professional collaboration between Mexican and Canadian surgical departments. This exchange, facilitated by the Red Cross, has developed into a departmental partnership that we hope will benefit patients in both countries. Future research will evaluate the experience of Mexican residents rotating at $\mathrm{VGH}$.

Acknowledgements: The authors would like to acknowledge the clinical teaching and support for this manuscript of Dr. Demian Trueba, Dra. Rita Valenzuela and the rest of the Cruz Roja faculty and health care workers.

Affiliations: From the Department of Surgery, University of British Columbia, Vancouver, B.C. (Margolick, Yin, Joharifard, Joos); the HCCR Polanco Cruz Roja, Mexico City, Mexico (Afya, Velez, Meza); the Canadian Red Cross, Ottawa, Ont. (Sohani); Trauma Services, Vancouver General Hospital, Vancouver, B.C. (Laane, Joos); the Branch for International Surgical Care, University of British Columbia, Vancouver, B.C. (Ball-Banting, Joos).

Funding: Funding for this project was provided by a research grant from the University of British Columbia Branch for International Surgical Care as well by the Mexican Red Cross.

Competing interests: None declared.

Contributors: J. Margolick, S. Joharifard, S. Sohani, C. Laane, E. Ball-Banting and E. Joos designed the study. J. Margolick, L. Yin, M. Velez and E. Joos acquired the data, which J. Margolick, L. Yin, A. Afya and E. Joos analyzed. J. Margolick, L. Yin, S. Joharifard, A. Afya, C. Laane and E. Joos wrote the manuscript, which J. Margolick, L. Yin, S. Joharifard, M. Velez, S. Sohani, E. Ball-Banting and E. Joos critically reviewed. J. Margolick, L. Yin, S. Joharifard, A. Afya, M. Velez, S. Sohani, C. Laane, E. Ball-Banting and E. Joos gave final approval of the article to be published.

\section{References}

1. Powell AC, Casey K, Liewehr DJ, et al. Results of a national survey of surgical resident interest in international experience, electives, and volunteerism. 7 Am Coll Surg 2009;208:304-12.

2. Harfouche M, Krowsoski L, Goldberg A, et al. Global surgical electives in residency: the impact on training and future practice at Temple University Hospital. Am 7 Surg 2018;215:200-3. 
3. Barton A, Williams D, Beveridge M. A survey of Canadian general surgery residents' interest in international surgery. Can f Surg 2008;51:125.

4. Inzaneghdar R, Carreia S, Ohata B, et al. Global health in Canadian medical education: current practices and opportunities. Acad Med 2008;83:192-8.

5. Mutchnick IS, Moyer CA, Stern DT. Expanding the boundaries of medical education: evidence for cross cultural exchanges. Acad Med 2003;78:S1-5.

6. Meara JG, Leather AJ, Hagander L, et al. Global surgery 2030: evidence and solutions for achieving health, welfare and economic development. Lancet 2015;386:569-624.

7. Shawar YR, Shiffman J, Spiegel DA. Generation of political priority for global surgery: a qualitative policy analysis. Lancet Glob Health 2015;3:e487-95.

8. VGH and UBC Hospital Foundation. Did you know? Quick facts about VGH's emergency department. Vancouver (BC): VGH and UBC Hospital Foundation; 2014 Mar 3. Available: https:// vghfoundation.ca/2014/03/03/did-you-know-quick-facts-about -vghs-emergency-department/ (accessed 2018 Sept. 28).

9. Lalande A, DeGirolamo K. Yirdaw. Challenges and successes: the establishment of a surgical partnership in Gondar, Ethiopia [presen- tation]. 23rd W.B. and M.H. Chung Research Day; 2018 Nov 5; Vancouver, B.C.

10. Oliphant JL, Ruhlandt RR, Sherman SR, et al. Do international rotations make surgical residents more resource-efficient? A preliminary study. 7 Surg Educ 2012;69:311-9.

11. Provincial Health Services Authority. Trauma Services BC 2015 annual report. Vancouver (BC): Trauma Services BC; 2015. Available: http:// www.phsa.ca/Documents/Trauma-Services/Trauma\%20Services\%20 BC\%202015\%20annual\%20report.pdf (accessed 2018 Sept. 23).

12. Durham R, Pracht E, Orban B, et al. Evaluation of a mature trauma system. Ann Surg 2006;243:775.

13. Hoff WS, Schwab CW. Trauma system development in North America. Clin Orthop Relat Res 2004;422:17-22.

14. Arreola-Risa C, Mock C, Vega Rivera F, et al. Evaluating trauma care capabilities in Mexico with the World Health Organization's Guidelines for Essential Trauma Care. Rev Panam Salud Publica 2006;19:94-103.

15. Dakermandji M, Boniface R, Gill HL, et al. Trauma: implementing trauma registries in Tanzania. In: Kusher AL, editor. Operation Health: surgical care in the developing world. Baltimore (MD): Johns Hopkins University Press; 2015. 